Authors have nothing to disclose with regard to commercial support.

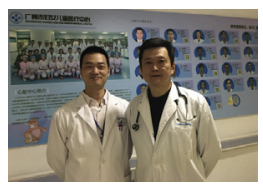

\section{DOES THE \\ APICOCAVAL JUXTAPOSITION FIT BETTER WITH A LATERAL TUNNEL OR AN EXTRACARDIAC CONDUIT?}

\section{To the Editor:}

We enjoyed the recent article by Weixler and colleagues, ${ }^{1}$ which shows an improvement in the survival of patients who underwent a Fontan operation with a lateral tunnel compared with an extracardiac conduit (EC). This study compared 638 patients who underwent the Fontan with the lateral tunnel with 163 patients who received the EC technique. The authors demonstrated that a lateral tunnel Fontan is associated with better short-term and midterm outcomes and that early spontaneous fenestration closure is an independent risk factor for mortality.

One additional aspect that would have been nice to explore is how these strategies adapt to patients with apicocaval juxtaposition (AJ). AJ is a morphologic feature of the cardiac apex that points to the ipsilateral side of the inferior vena cava (IVC) and therefore may complicate a Fontan procedure. This malformation may be present in up to approximately $14.7 \%$ to $24.2 \%$ of patients undergoing the Fontan procedure. ${ }^{2-4}$

If an EC between the IVC and the contralateral pulmonary artery is used, the long curve route crosses the spine and can cause kinking and severe energy loss. On the other hand, if the conduit is connected to the ipsilateral pulmonary artery, this is confined to the narrow space behind the ventricle and compression from the ventricle. Beyond these techniques, an intracardiac/EC was proposed. ${ }^{5}$ However, a conduit inside the atrium may disturb the pulmonary venous flow and cause pulmonary venous obstruction, especially for patients with totally anomalous pulmonary venous connection. We recently reported 31 cases of patients who underwent the Fontan with $\mathrm{AJ}^{4}{ }^{4}$ The chosen

\footnotetext{
The Editor welcomes submissions for possible publication in the Letters to the Editor section that consist of commentary on an article published in the Journal or other relevant issues. Authors should: • Include no more than 500 words of text, three authors, and five references. • Type with double-spacing. • See http://jtcs.ctsnetjournals.org/ misc/ifora.shtml for detailed submission instructions. • Submit the letter electronically via jtcvs.editorialmanager.com. Letters commenting on an article published in the JTCVS will be considered if they are received within 6 weeks of the time the article was published. Authors of the article being commented on will be given an opportunity of offer a timely response ( 2 weeks) to the letter. Authors of letters will be notified that the letter has been received. Unpublished letters cannot be returned.
}

conduit route was a connection between the IVC and the ipsilateral pulmonary artery in 24 patients and a connection to the contralateral pulmonary artery in 5 patients. An intracardiac/EC was used in another 2 patients. Our current preference is to place the conduit between the IVC and the ipsilateral pulmonary artery to create a straight route and minimize energy loss.

Although a complete evaluation of the impact of hemodynamics on thromboembolic events has not been conducted, the results are promising. Fenestrations closed early, and this may suggest an inferior hemodynamic performance. However, concern remains for $\mathrm{AJ}$ as a risk factor for early spontaneous fenestration closure. Additionally, a consensus has not been reached on the use of warfarin in patients with risk factors for lower hemodynamics, such as AJ, totally anomalous pulmonary venous connection, and atrioventricular valve regurgitation.

AJ complicates the Fontan operation. The lateral tunnel Fontan procedure seems to exploit an advantage of less energy loss. However, current reports have not yet shown which approach is superior in patients with $\mathrm{AJ}$ requiring the Fontan operation.

Weidan Chen, $M D^{a, b}$
Alvise Guariento, $M D^{b}$
Xinxin Chen, $M D^{a}$
${ }^{a}$ Cardiovascular Center
Guangzhou Women and Children's Medical Center
Guangzhou Medical University
Guangzhou, China
${ }^{b}$ Labatt Family Heart Center
Hospital for Sick Children
Toronto, Ontario, Canada

\section{References}

1. Weixler VHM, Zurakowski D, Kheir J, Guariento A, Kaza AK, Baird CW, et al Fontan with lateral tunnel is associated with improved survival compared with extracardiac conduit. J Thorac Cardiovasc Surg. 2020;159:1480-91.

2. Morizumi S, Kato H, Kanemoto S, Noma M, Abe M, Sakakibara Y, et al Appropriate route selection for extracardiac total cavopulmonary connection in apicocaval juxtaposition. Ann Thorac Surg. 2012;94:179-84.

3. Sakurai T, Kado H, Nakano T, Hinokiyama K, Oda S, Sugiura J, et al. The impact of extracardiac conduit-total cavopulmonary connection on apicocaval juxtaposition. Eur J Cardiothorac Surg. 2010;38:439-44.

4. Chen W, Lu Y, Ma L, Yang S, Xia Y, Zou M, et al. Conduit route selection for total cavopulmonary connection in patients with apicocaval juxtaposition. Semin Thorac Cardiovasc Surg. 2019;31:104-9.

5. Sinha L, Ozturk M, Zurakowski D, Yerebakan C, Ramakrishnan K, Matisoff A, et al. Intra-extracardiac versus extracardiac Fontan modifications: comparison of early outcomes. Ann Thorac Surg. 2019;107:560-6.

https://doi.org/10.1016/j.jtcvs.2020.02.094 